\title{
«NÓS SOFREMOS VIOLÊNCIA TODO DIA!»: REPRESENTAÇÕES SOCIAIS E VIVÊNCIAS DE VIOLÊNCIA PARA PESSOAS TRANSGÊNERAS
}

\section{«WE SUFFER VIOLENCE EVERYDAY!»: SOCIAL REPRESENTATIONS AND VICTIMS OF VIOLENCE FOR TRANSGENDERS}

\author{
Luiz Paulo Ribeiro - Centro Universitário de Belo Horizonte (UniBH) \\ luizribeiro@live.com \\ Fabiana Bacellar Vilanni \\ Ivan Paulo da Silva \\ Patrícia Tamara de Souza Alexandre
}

Resumo O Brasil se tornou, nos últimos anos, o país que mais mata travestis e transexuais no mundo e, diante disso, há que se questionar como a violência é pensada e sentida por estes sujeitos. Este estudo analisou as representações sociais (RS) sobre a violência para a população "T" (transgênera) de Belo Horizonte. Para tanto, foram realizadas og (nove) entrevistas semiestruturadas e uma análise de conteúdo através do software Iramuteq $^{\circledR}$. Os sujeitos entrevistados são pessoas travestis e transexuais que residem em Belo Horizonte/MG, incluídos/as por disponibilidade e conveniência. A RS da violência está relacionada com o que é vivido pessoal e socialmente por essa população, o que está organizada em quatro classes: (a) vivências; (b) instituições e processo transicional; (c) identidade e gênero; e (d) corpo e vivência social. Diante da violência real, histórica e vivencial para com as pessoas transgêneras analisadas, nota-se a necessidade de ações governamentais de suporte a essa população que tem marcas da violência na sua história, experiência social e formas de pensar, sentir e agir.

Palavras-chave: violência; pessoas transgêneras; representações sociais; identidade de gênero; iramuteq;

\footnotetext{
Abstract Brazil is the country where there are more cases of transvestite and transsexual murders in the world, and, on the face of it, it is necessary to know how violence is thought and felt by these subjects. This study analyzed the social representations (RS) about violence for the "T" (transgender) population of Belo Horizonte. For this purpose, 9 (nine) semi-structured interviews and content analysis were carried out through Iramuteq ${ }^{\circledR}$ software. The subjects interviewed are transvestite and transsexual people residing in Belo Horizonte / MG, included for availability and convenience. The RS of violence is related to what is lived personally 
and socially by this population, and is organized into four classes: (a) experiences (b) institutions and transitional process, $(c)$ identity and gender and (d) body and social experience. Faced with real, historical and experiential violence towards transgendered people analyzed, there is a need for government actions to support this population that has marks of violence in its history, social experience and ways of thinking, feeling and acting.

Keywords: violence; transgender people; social representations; gender identity; iramuteq.

\section{Introdução}

Por definição, diz-se que transgênero é um termo 'guarda-chuva' utilizado para conceituar e descrever o comportamento gênero-divergente de um indivíduo, ou seja, quando a identidade e/ou a expressão de gênero diverge, descumpre, viola, fere, afronta, conflita ou não está em conformidade com o binarismo de gênero em que determinado indivíduo foi classificado ao nascer (Lanz, 2014). Estes indivíduos gênero-divergentes fazem parte do que Lanz (2014) conceitua como 'transgeneridade': um fenômeno sociológico de desvio ou transgressão do dispositivo binário de gênero, abarcando as identidades gênero-divergentes, tais como transexuais, travestis, crossdressers, dragqueens, andróginos, etc.

Embora a questão da transexualidade esteja cotidianamente ocupando os espaços das mídias sociais e televisivas no Brasil (Itaqui \& Felippi, 2017), o que tem se visto é que este país continua paradoxalmente sendo o que mais mata transexuais e travestis no mundo (Transgender Europe, 2017), como também é o país em que os índices de busca por conteúdo pornográfico com pessoas trans são os mais acessados (Rocha, Ban, \& Valenga, 2017). Essa lógica de uso e de cultura da violência contra as pessoas transgêneras (travestis e transexuais) reflete a vivência social desses sujeitos que, por vezes, por estarem na marginalidade e extrema vulnerabilidade, acabam por encontrar na prostituição a única saída para o enfrentamento das suas vulnerabilidades. Na prostituição são usados/as como fetiches sexuais, objetos de prazer e, muitas vezes, como descartáveis, sendo inúmeros os casos de assassinatos de pessoas transgêneras após a realização de 'programas'.

Ainda que seja uma situação que desperta a tristeza e a indignação, a situação de violência contra as pessoas transgêneras vai além da questão da prostituição. É, muitas vezes, na família, no processo transicional que esses sujeitos vivenciam grande parte de suas violências; rejeição, expulsão de casa, humilhações e culpabilizações, etc. fazem com que estes sujeitos rompam seus vínculos familiares tenramente, sendo raros, nas camadas mais populares, registros de aceitação da família sobre a transexualidade dos filhos (Efrem Filho, 2016).

Se a série de violências contra as pessoas transgêneras se inicia no ambiente familiar, a vivência na escola e no acesso a outras políticas públicas, como a de saúde, não ficam de fora do hall de violências sofridas. Na escola, além do bullying e da transfobia sofridos cotidianamente e praticados por parte dos demais alunos, as pessoas transgêneras encontram problemas na utilização das dependências da escola, como o vestiário e o banheiro (Cruz, 2011; Efrem Filho, 2016). Por outro lado, algumas 
vezes, os profissionais da escola, que deveriam promover um lugar de protagonismo escolar e de convívio com as diferenças, acabam por fazer o contrário: auxiliam na cultura da estigmatização, não promovem o diálogo e o respeito. Essas condutas incidem na baixa escolaridade das pessoas transgêneras, uma vez que, não sendo acolhidas no ambiente escolar, evadem da escola, incidindo diretamente na atuação profissional desses sujeitos (Souza \& Bernardo, 2014).

No sistema de saúde, o preconceito dos profissionais também incide diretamente na qualidade do atendimento às pessoas transgêneras, provocando desumanização e não atenção às suas especificidades (Silva, et al., 2016). Na política pública de saúde brasileira, a violência parte desde o não respeito ao uso do nome social até a ações vexatórias e discriminatórias durante os atendimentos, além de condutas que a diagnosticam como doença (Arán, Murta, \& Lionço, 2009). Embora exista o "processo transexualizador do SUS" (Brasil, 2013), uma orientação da política pública para que as pessoas transgêneras sejam acolhidas e respeitadas na sua individualidade e no seu processo de saúde-adoecimento, ainda há barreiras na sua implantação e dispersão em todos os níveis de atenção à saúde. Entretanto, demarca-se que esta orientação, que também se tornou uma legislação, é um avanço anti-hegemônico.

Como mencionado anteriormente, se estes sujeitos não possuem apoio familiar, acabam por encontrar na prostituição abrigamento, renda e uma inclusão social, mesmo que possa ser considerada disfuncional. Se não têm na política pública de saúde atenção às suas necessidades, recorrem a instituições clandestinas e ao uso de materiais impróprios para a obtenção de resultados em relação ao uso de hormônios e procedimentos estéticos na adequação do corpo à identidade de gênero (Ventura, 2010). Na escola ainda enfrentam transfobia e preconceito e essas situações incidem diretamente na sua inserção no mercado de trabalho - a informalidade e a baixa qualificação profissional, além da necessidade de ter que omitir ao máximo sua transexualidade para se manter no trabalho (Carrieri, Souza, \& Aguiar, 2014), além de influenciar na sua expectativa de vida e práticas sociais vulnerabilizantes. As situações aqui relatadas, por si só, revelam um ciclo de violência que persiste junto à população trans e travesti no Brasil.

Diante disso, verifica-se que a população travesti e transexual encontra violências no seu cotidiano, mas o que esses sujeitos pensam, sentem e como agem diante desse fenômeno? Como eles a vivenciam e quais as suas propostas para a melhoria do quadro social e o alcance de direitos sociais já conquistados? Assim, a proposta deste artigo é analisar, através da teoria das representações sociais, como a violência é sentida e representada por sujeitos transexuais e travestis de Belo Horizonte, no estado de Minas Gerais, Brasil.

Parte-se do pressuposto que violência, segundo Ribeiro (2017), é um fenômeno social que pode ser notado em diferentes sociedades e culturas. Por assim ser, este fenômeno tem relação com as formas de exercer o poder e dos padrões de sociabilidade. Este autor afirma que a lógica sociabilizante dos atos de violência pode ser justificada pelas práticas culturais instaladas e que não há como "vivenciar a violência sem a produção de algo" (p. 36). Ou seja, a violência não é algo restrito à população travesti e transexual, porém, por existir uma cultura que ainda é machista, patriarcal e cis-heteronormativa, ela acaba sendo permitida e massivamente ocasionada pelo ódio e LGBTfobia. 
Entretanto, contra-argumenta-se que, por ser um produto social, as situações de violência demonstram ser passíveis de modificação do seu status quo, ou seja, mesmo frente à verificação de um extenso rastro de violência contra a população transgênera, há que se acreditar e lutar pela superação desta a partir da divulgação, conscientização, protagonismo e reconhecimento das diferentes formas de identidade de gênero e prática sexual.

Por outro lado, utilizar a Teoria das Representações Sociais (Moscovici, 2012) significa entrar em contato com a vivência da violência por parte das pessoas transexuais e de como as formas de pensar, sentir e agir desses sujeitos são mobilizadas diante desse fenômeno. Por sua vez, Jodelet (2005) evidenciou que as experiências vividas contribuem significativamente para a construção social-subjetiva da realidade, ou seja, "o sistema global de representações fornece os recursos e os instrumentos para interpretar aquilo que é experimentado [ao passo que] essa experiência dá sentido ao vivido que estrutura" (Jodelet, 2005, p. 48).

A Teoria das Representações Sociais (TRS) tem sua origem na Psicologia Social e na Psicossociologia e expressa "[...] conjuntos dinâmicos, [...] a produção de comportamentos e de relação com o ambiente, da ação que modifica uns e outros [...]" (Moscovici, 2012, p. 47), ou seja, envolve a busca do entendimento sobre a dinâmica individual e social a qual mobiliza os sujeitos a sentir, pensar e agir. A representação social é algo vivo, que está imbricada com a intenção e a interação entre o sujeito e a sociedade, numa relação intensa, de ir e vir, na qual tanto o sujeito quanto a sociedade produzem e reproduzem conceitos, símbolos e imagens (Moscovici, 2012).

Apesar dos estudos envolvendo as RS e a transexualidade/travestilidade já serem comuns (Santos, Shimizu, \& Merchan-Hamann, 2014; Baptista, Silva, Menandro, \& Bonomo, 2016; Matão, Miranda, Campos, Teles, \& Mesquita, 2010; Arbatani, Aqili, Labafi, \& Omidi, 2016), ainda são escassos os estudos que incluem tais sujeitos como participantes (Caravaca-Morera \& Padilha, 2017), havendo um espaço profícuo para este campo de pesquisas.

\section{Métodos e Sujeitos}

Este estudo trata-se de uma pesquisa qualitativa descritiva com sujeitos transgêneros do município de Belo Horizonte, no estado de Minas Gerais, Brasil. É, pois, uma pesquisa dentro do paradigma da Teoria das Representações Sociais (Moscovici, 2012; Jodelet, 2005). Para tanto foram feitas o9 (nove) entrevistas semiestruturadas com sujeitos transexuais que se disponibilizaram a participar da pesquisa.

Não existem estudos que possam trazer uma estimativa sobre o contingente populacional de pessoas transgêneras no Brasil ou no município de Belo Horizonte, entretanto, como em Cunha \& Rios (2006), a partir da amostragem feita nos Estados Unidos, as estimativas de população transgênera estão entre $0,6 \%$ a $2,8 \%$ da população total. Partindo dessas proposições, estima-se que em Belo Horizonte, capital do estado de Minas Gerais, localizada na região Sudeste do Brasil, existam entre 15.142 e 70.666 pessoas transgêneras. Este número é ao mesmo tempo 
expressivo e questionador, já que demonstra a amplitude dos problemas que estes sujeitos vivem, além de permitir perguntar: onde estão estas pessoas?

Partindo de uma amostragem não probabilística e intencional diante das estimativas populacionais, cogitou-se inicialmente fazer este estudo com 30 sujeitos e assim foram feitos convites para conseguir atingir esta amostra. Porém, os pesquisadores encontraram dificuldades no processo de inclusão dessa população no estudo, uma vez que, devido ao extenso rastro de violência e do aumento de pesquisas sem retorno aos mesmos, estes sujeitos têm se recusado a participar dos estudos que os envolvem. Houveram negativas de participação que evidenciam a especulação midiática e acadêmica sobre o assunto, assim como aqueles que se negaram como resistência à participação em uma pesquisa feita por sujeitos cisgêneros. Assim, a amostra se tornou reduzida, og (nove) sujeitos se disponibilizaram a participar das entrevistas. Apesar disso, estes sujeitos foram considerados prototípicos e permitem reconhecer as violências que estes sujeitos sofrem. Há que se pontuar também que as formas de pensar, sentir e agir representações sociais - são construídas e reproduzidas socialmente (Moscovici, 2012; Jodelet, 2005) e, por isso, torna-se possível fazer um estudo validado diante dessa teoria mesmo com uma população reduzida, como, por exemplo, a tese de Carvalho (2017).

O quadro 01 traça o perfil socioeconômico dos/das participantes da pesquisa. Coloca-se como observação que o critério identitário foi feito por autodenominação, ou seja, os/as participantes foram questionados/as sobre qual identidade de gênero eles/elas se assumiam. Este critério foi altamente respeitado.

\begin{tabular}{|c|c|c|c|c|c|}
\hline $\mathrm{n}$ & Idade & $\begin{array}{c}\text { Identidade de } \\
\text { Gênero }\end{array}$ & $\begin{array}{c}\text { Nível de } \\
\text { Escolaridade }\end{array}$ & Renda Mensal & $\begin{array}{l}\text { Vínculo de } \\
\text { trabalho }\end{array}$ \\
\hline A & 54 & $\begin{array}{c}\text { Mulher } \\
\text { Transexual }\end{array}$ & $\begin{array}{l}\text { Ensino Médio } \\
\text { Completo }\end{array}$ & $\begin{array}{c}\text { Acima de } 5 \\
\text { salários mínimos }\end{array}$ & $\begin{array}{l}\text { Profissional do } \\
\text { Sexo - Professora }\end{array}$ \\
\hline B & 30 & $\begin{array}{c}\text { Mulher } \\
\text { Transexual }\end{array}$ & Ensino Técnico & $\begin{array}{l}\text { Até } 5 \text { salários } \\
\text { mínimos }\end{array}$ & Cabelereira \\
\hline $\mathrm{C}$ & 33 & $\begin{array}{c}\text { Mulher } \\
\text { Transexual }\end{array}$ & $\begin{array}{l}\text { Ensino Médio } \\
\text { Completo }\end{array}$ & $\begin{array}{c}\text { Acima de } 5 \\
\text { salários mínimos }\end{array}$ & $\begin{array}{l}\text { Profissional do } \\
\text { Sexo }\end{array}$ \\
\hline$D$ & 24 & $\begin{array}{l}\text { Homem } \\
\text { Transexual }\end{array}$ & $\begin{array}{l}\text { Ensino Médio } \\
\text { Completo }\end{array}$ & $\begin{array}{l}\text { Menos de } 01 \\
\text { salário mínimo }\end{array}$ & Não possui \\
\hline$E$ & 23 & $\begin{array}{c}\text { Mulher } \\
\text { Transexual }\end{array}$ & Ensino Técnico & $\begin{array}{l}\text { Menos de o1 } \\
\text { salário mínimo }\end{array}$ & Modelo \\
\hline$F$ & 34 & $\begin{array}{c}\text { Mulher } \\
\text { Transexual }\end{array}$ & $\begin{array}{l}\text { Ensino Médio } \\
\text { Incompleto }\end{array}$ & $\begin{array}{l}\text { o1 salário } \\
\text { Mínimo }\end{array}$ & $\begin{array}{l}\text { Profissional do } \\
\text { Sexo }\end{array}$ \\
\hline G & 26 & $\begin{array}{c}\text { Travesti } \\
\text { Transfeminina } \\
\text { Não-Binária }\end{array}$ & $\begin{array}{l}\text { Ensino Médio } \\
\text { Completo }\end{array}$ & $\begin{array}{l}\text { o1 salário } \\
\text { mínimo }\end{array}$ & Autônoma \\
\hline $\mathrm{H}$ & 41 & $\begin{array}{c}\text { Mulher } \\
\text { Transexual }\end{array}$ & Ensino Superior & $\begin{array}{c}\text { De } 2 \text { a } 5 \text { salários } \\
\text { mínimos }\end{array}$ & Vínculo Celetista \\
\hline I & 26 & $\begin{array}{c}\text { Homem } \\
\text { Transexual } \\
\text { Não-Binário }\end{array}$ & $\begin{array}{l}\text { Ensino Médio } \\
\text { Completo }\end{array}$ & $\begin{array}{l}\text { Menos de } 01 \\
\text { salário mínimo }\end{array}$ & Desempregado \\
\hline
\end{tabular}


Por sua vez, o protocolo de perguntas que foi utilizado nas entrevistas foi construído a partir de pressupostos da teoria das representações sociais, construindo questões que possibilitassem descrever a experiência dos sujeitos diante do objeto violência, analisá-lo e prescrever ações diante do mesmo. Por outro lado, também atentou-se para as dimensões da representação social na construção das questões, buscando ser possível identificar fontes de informação, elementos contextuais e atitudinais dos sujeitos (Ribeiro \& Antunes-Rocha, 2016).

As entrevistas semiestruturadas foram coletadas entre os meses de junho e outubro do ano de 2017. Todos os sujeitos, resguardando-se os padrões éticos em pesquisa, foram submetidos ao Termo de Consentimento Livre e Esclarecido (TCLE). Suas falas foram transcritas na íntegra e suas identidades foram preservadas, retirando-se todos os elementos que permitissem tal identificação. Neste artigo os/as participantes serão referidos/as apenas por letras do alfabeto.

Após as entrevistas feitas e os dados transcritos, foi feita uma leitura atenta de todo o corpus textual verificando possíveis temáticas presentes nas falas dos/das participantes. Os dados já categorizados foram tratados através da análise de conteúdo por categorias conjugada com a análise léxica (Camargo \& Justo, 2013) com o auxílio do software IRAMUTEQ (interface de $R$ pour les analyses multidimensionnelles de textes et de questionnaires). A saber, este software é livre, tem origem francesa e é utilizado nas pesquisas sobre representações sociais por ser similar ao ALCESTE. Seu método consiste na identificação de categorias e relações entre as mesmas, mapeando um vocabulário típico de cada categoria, contrapondo as variáveis grupais e possibilitando o reconhecimento de classes na representação social.

\section{Apresentação e análise de dados}

O material analisado pelo IRAMUTEQ foi composto por og unidades de contexto inicial (UCl) ou entrevistas e foi dividido em 795 unidades de contexto elementar (UCE), sendo estas retidas e utilizadas para esta análise. O software utilizado subdividiu o corpus em quatro classes a partir da classificação hierárquica descendente (CHD), constituindo o dendograma presente na figura 01. 


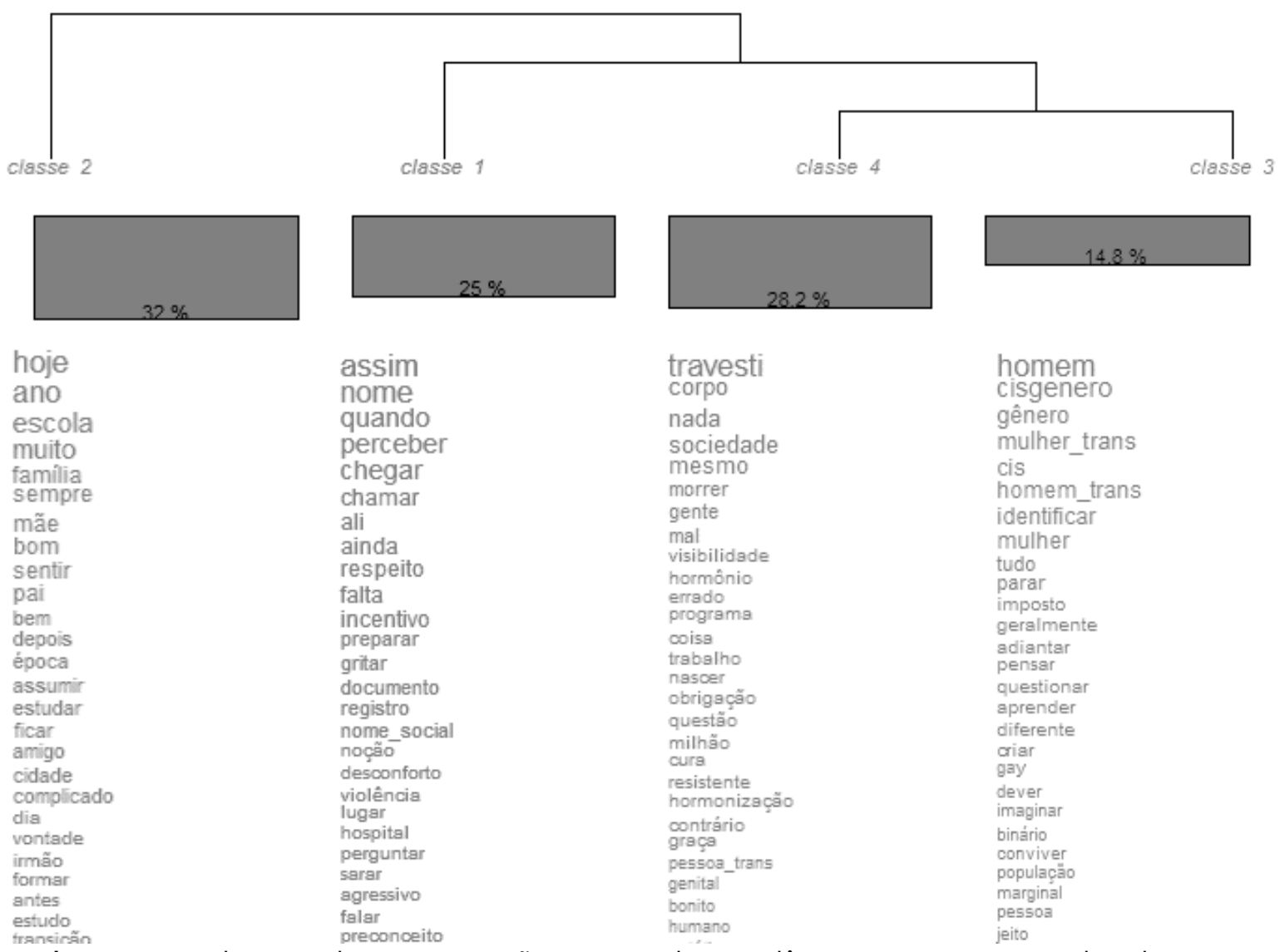

Figura 01: Dendograma das representações sociais sobre a violência para sujeitos trans de Belo Horizonte $(n=9)$. Fonte: Dados da pesquisa (2017).

As classes subdividem o corpus textual a partir da correlação lexical, assim como a presença/ausência em cada um dos trechos das entrevistas, o software também utiliza das variáveis grupais e individuais para construir as correlações entre as classes (Camargo \& Justo, 2013). Estas classes estão apresentadas conforme a organização do próprio software IRAMUTEQ, estando articuladas com os parâmetros lexicais do mesmo.

A classe dois foi denominada instituições e processo transicional, constituída por $32,02 \%$ do corpus, sendo a maior das classes. Esta classe possui elementos da vivência em família e escola, traz também como a transição - reconhecer, viver e assumir a transexualidade - aconteceu e como as instituições já elencadas participaram desse movimento. As palavras 'hoje', 'ano', 'escola', 'muito', família', 'sempre', 'mãe', 'bom', 'sentir', 'pai', entre outras, são as mais frequentes nessa classe.

A representação social da violência passa pela sua vivência histórica em oposição à realização do hoje. Ser transexual 'hoje' diz respeito à transição e ao que se sofreu na família e na escola até chegar ao estágio atual, como se avalia no presente.

[...] foi surgindo e há 4 anos e meio atrás eu vim tomar hormônio para poder ficar igual mulher, mas, porém, eu já me visto de mulher já tem mais ou menos uns 8 a 9 anos. (Entrevistada $\mathrm{H}$, mulher transexual) 
[os amigos te aceitam?] Os amigos sim, porque assim que eu me assumi trans logo depois de 1 ano eu adotei o meu nome, hoje em dia [...] todo mundo já me conhece. (Entrevistada $\mathrm{H}$, mulher transexual)

Assim como a apropriação da identidade trans, assumir para si e para os outros faz parte de um processo de aceitação que pode ou não conter traços ou percepções de violência. Este processo de coming out (sair do armário, na tradução para o português), de se assumir ou tomar consciência da identidade " $T$ ", pode ser, por si só, elemento gerador de violência, tudo dependerá do contexto em que este se desenvolve e como as pessoas reagem (Geoffroy \& Chamberland, 2015). Nesse percurso, a utilização da palavra 'ano' é instrumento de demarcação dos espaços de tempo, diante das experiências.

Eu fiquei muitos anos na Europa, não tive vontade de vir embora para o Brasil porque lá a gente é tratada como uma mulher normal, então não existe este preconceito. (Entrevistada A, mulher transexual)

O processo de assumir foi bem tranquilo porque eu já havia me identificado como transexual há mais de quatro anos. Eu apenas pesquisei bastante porque eu sabia que a qualquer momento alguém ia tentar deslegitimar o que estava falando que eu era. Eu saí de uma caixinha que estava me aprisionando há muitos anos [...] de certa forma prejudicou muito a minha vida. (Entrevistada G, travesti, transfeminina, não-binária)

Diante dessas experiências, a família e seus entes e a escola e seus profissionais assumem um papel marcante nessa classe, uma vez que é nela que as primeiras socializações da sexualidade acontecem, local também das primeiras situações de violência. A descoberta da transexualidade na infância (Rodrigues \& Barros, 2016) e na escola (Souza \& Bernardo, 2014) é avaliada como mais difícil já que encontra barreiras em lugares que seriam promotores da liberdade e da aceitação.

Mas eu acho que se eu tivesse descoberto a minha transição no período da escola eu acho que seria muito mais difícil e é mais difícil pra galera que se descobre no período escolar tanto na infância. (Entrevistado D, homem transexual)

Fui proibida de frequentar a escola, falaram que eu podia ser uma má influência para os alunos. A escola não me aceitou por ser uma cidade pequena, aí foi um choque. (Entrevista $D$, mulher transexual)

Bom, minha vivência na escola, eu era uma pessoa muito comunicativa, muito amiga das pessoas, então como se diz, eu fiz do limão uma limonada. (Entrevistada B, mulher transexual)

Se por um lado a violência aparentemente não existe na escola, o que se percebe é que ela está presente e, para sobreviver nela, os sujeitos acabam encontrando saídas para o enfrentamento, por vezes negando ou se acostumando com a violência, ou 'transformando um limão em uma limonada' (sic, entrevistada B), ou seja, convive com a violência e encontra formas até caricatas ao extremo para angariar o afeto dos 
sujeitos presentes. No relato ainda é possível verificar a negação do direito ao acesso à escola. Neste caso, a participante aceita a violência sofrida.

Em relação à instituição família, está representada nessa classe pela indicação às palavras 'família', 'mãe', 'pai', 'irmão' e 'amigo', relacionadas à existência de uma rede de apoio social dos/as participantes da pesquisa. Nessa classe, a importância da família no processo de aceitação diz respeito à presença ou não de facilidades de enfrentamento às violências, assim como, pode ser motor para a existência dessas, como afirma Soares et al (2011).

Olha, na verdade, essa aceitação de ser uma transexual é um pouco complicada, porque minha mãe biológica nunca aceitou por eu ser homossexual, já minha mãe adotiva sempre me aceitou. [...] A família no começo não acredita, acha que é uma loucura (Entrevistada B, mulher transexual)

A minha família, graças a Deus, ninguém teve preconceito, só que me acolher também ninguém me acolheu, é uma coisa irônica né?! (Entrevistada G, travesti, transfeminina, não-binária)

Bom, no caso, tipo assim, eu sou uma pessoa abençoada, porque na minha casa quando eu sentei para falar de transexualidade com a minha família, foi com uns 19 anos, eu não entendia [...] (Entrevistada E, mulher transexual)

Você tem que lutar pelo que você quer, eu poderia ter seguido todos os conselhos de meu pai e minha mãe. Eles nunca falaram não comigo, só sentavam. Tudo que eu ia fazer meu pai: vamos sentar, vamos conversar? (Entrevistada A, mulher transexual)

Por outro lado, a família da pessoa transgênera também é questionada pelas outras instituições sobre a orientação sexual e identidade de gênero dos filhos. Há casos em que a escola não aceita o processo transicional que vive a criança/adolescente, fazendo com que o sujeito seja expulso ou, pela insistência, abandone a escola (Cruz, 2011; Souza \& Bernardo, 2014).

Assim, uma entrevistada relatou: "A diretora da escola sempre chamava minha mãe e meu pai: ai, tem alguma coisa errada com seu filho, ele não quer fazer educação física, não quer jogar futebol [...]" (Entrevistada A, mulher transexual). Se por um lado a família e a escola são instituições que marcam a trajetória transicional das pessoas entrevistadas, por outro lado pode-se inferir que estas mesmas instituições são responsáveis por, no processo de transição, ser ou não elemento gerador de violências. Conforme apontam Soares et al (2011), uma família que acolhe, orienta e procura, apesar das muitas dúvidas que possam surgir, entende o que se passa com o sujeito transgênero, assim como uma escola que desenvolve o respeito à diferença e à diversidade promove o protagonismo e erradica o preconceito, que são essenciais para uma mudança cultural e da sociedade em respeito às diferentes identidades de gênero e sexualidades.

A classe um foi denominada vivências da violência, constituída por $24,96 \%$ do corpus. Esta classe possui elementos de como a violência é vivida, percebida e sentida em diferentes ambientes e ocasiões, ou ainda as práticas de violências e as reações dos sujeitos. As expressões 'assim', 'nome', 'perceber', 'respeito', 'preparar', 'registro', 'nome social', 'desconforto', 'violência', 'preconceito', entre outras, são as mais 
frequentes nessa classe. Se torna interessante notar que grande parte dos trechos dessa classe dizem respeito àqueles estabelecidos anteriormente como pertencentes ao acesso e utilização das políticas públicas de saúde e educação.

Para além do processo de descobrir/assumir a transexualidade, essa classe traz em si como a violência contra os sujeitos transgêneros se faz desde estruturas mais elementares, como a enunciação do nome, do nome social. Essa violência, muitas vezes cometida com ou sem motivação, tem duas faces, pois deslegitima a identidade ao mesmo tempo que proporciona desconforto e insatisfação. Os trechos das entrevistas abaixo corroboram Bento (2014) e evidenciam a precariedade da cidadania das pessoas transgêneras em relação ao nome social.

Olha, você não é tratada como uma pessoa normal enquanto você não tem no seu registro [RG]. (Entrevistada $\mathrm{E}$, mulher transexual)

É necessário lidar com o preconceito: lidar com o nome que tá no RG, lidar com o corpo [...]. (Entrevistado I, homem transexual não-binário)

Você chega a estes ambientes, tá seu nome social lá, porém a pessoa ainda chama pelo nome de registro, é por provocação porque não tem outro motivo né. (Entrevistado D, homem transexual)

Dependendo do profissional, como a gente bem disse, se não tiver preparo, você vai sofrer algum tipo de desconforto, seja no chamar o nome ou seja na forma de tratamento. (Entrevistada B, mulher transexual)

O direcionamento, a atuação dos profissionais da saúde diz respeito à vivência que se repete em diferentes casos em que a identidade de gênero, embutida na utilização de um nome social, não é respeitada. Isso acontece na atuação profissional e revela o despreparo, além da ausência de utilização de condutas em respeito à população trans (Arán, Murta, \& Lionço, 2009). Embora erros de formação existam, uma das entrevistadas afirma que esta forma de preconceito acontece porque:

A sociedade é muito machista, querendo ou não até mesmo muitas mulheres são machistas e dependendo do ciclo do trabalho é, querendo ou não, algum tipo de machismo impera e quando é numa situação dessas você percebe como o machismo é sufocante. (Entrevistada E, mulher transexual)

Entretanto, outra entrevistada afirma que é uma questão de percepção, que o uso do nome social é um sintoma de um sistema carregado de preconceitos, muito embora ela tenha esperança que seja possível conscientizar, mudar a situação, fazer perceber.

Mas quando elas, tipo assim, perceberem a noção disso, elas vão se policiar, ter mais cuidado, mais respeito, sabe? (Entrevistada $\mathrm{E}$, mulher transexual)

Dessa forma, a questão do respeito não é tratada como algo natural, sendo necessária a conscientização (Santos, Shimizu, \& Merchan-Hamann, 2014). Por outro lado, a falta de respeito deve ser combatida pelo medo, por meios jurídicos e a polícia 
deve influenciar na imposição do respeito: o respeito se faz necessário diante da possibilidade da violência.

Aqui porque tu é louca tá, sabe, não tem um processo de respeito natural. 0 respeito não vem de forma natural, ele tem que vir pelo medo, tipo, não mexe com aquele viado não que ele é louco, mais ou menos assim. (Entrevistada G, travesti, transfeminina, não-binária)

Eu acho que elas deveriam primeiramente ser atendidas como seres humanos, com respeito, entendeu, independente da situação sexual, porque não é opção, opção é quando você pode optar por uma coisa. (Entrevistada B, mulher transexual)

Ah, eu queria a respeito da violência que está tendo agora, este monte de morte de transexuais e a polícia deveria se empenhar mais né, você vê a maioria dos casos que aconteceu esse ano quase nenhum foi resolvido ainda não resolveu nada ainda. (Entrevistada $A$, mulher transexual)

Sim, então é aí eu acredito assim muitas coisas, tipo assim, que a gente sofre assim de violência e é constante essa falta de respeito em questão de seu gênero. (Entrevistada $E$, mulher transexual)

Neste sentido, a vivência da violência deixa marcas físicas e psicológicas, notadas na enunciação da própria palavra 'violência', que é difícil de ser dita. Entretanto, a violência é vivenciada todos os dias em diversos espaços e ocasiões. Nestas falas os/as participantes também tentam definir o que é violência para eles/elas.

Não vou falar violência, que eu acho, tipo assim, uma palavra muito pesada, mas gera sim, um desconforto assim psicológico para você. (Entrevistada $E$, mulher transexual)

[violência é] qualquer forma de opressão, quando querem te oprimir, quando não querem deixar você ser quem você é, isso já é uma violência, e é a maior das violências, porque é a maior prisão sem muros. [...] Nós sofremos violência todos os dias. Como eles fazem, o que eles fazem para nos ajudar, isso não tem ajuda. (Entrevistada C, mulher transexual)

Eu lembro em vários eventos já aconteceu das pessoas no meio da merenda pegar um prato de comida e jogar no meio da minha cara e, assim, isso era tido na escola apenas como uma violência entre adolescentes, porque teve uma rixazinha ali na hora na cantina, sabe? (Entrevistada G, travesti, transfeminina, não-binária)

Dessa forma, essa classe diz respeito ao modo como as experiências sociais auxiliam na construção da consideração do que é ou não violência, conforme Ribeiro (2017), diante das vivências do/da transexual e da travesti, o que é ratificado como violência por si e pela sociedade. O que se percebe é que na trajetória de vida de cada um dos/das participantes sobram fatos - que podem ser considerados muitos - que podem ser qualificados como violência, muitos deles nem o próprio sujeito o indica assim, mas o sente. Dois elementos evidenciados por Ribeiro (2017) são importantes 
em relação à violência. O primeiro diz respeito às violências justificadas, ou seja, em alguns casos a violência contra as pessoas transgêneras é justificada seja pelo ódio, seja pelas questões religiosas, seja pela transgressão da norma cisgênera. Em segundo lugar, a violência se torna algo tão comum para os sujeitos transgêneros que pode cair na representação de que é algo naturalizado, ou seja, "normal" para estes sujeitos.

Por sua vez, a classe quatro foi denominada corpo e vivência social, constituída por $28,24 \%$ do corpus. Essa classe está em conformidade com o que é apresentado por Lanz (2014), que demonstra como o corpo do/da transexual e da travesti é elemento marcante da forma como a sociabilidade é vivenciada (Geoffroy \& Chamberland, 2015; Ventura, 2010). Essa classe tem em grande parte de sua composição a categoria preestabelecida como redesignação sexual, ou seja, trechos em que o/a participante diz sobre o desejo ou não de fazer cirurgias de 'adequação' da genitália. Dessa forma, a transformação do corpo pode ser o que traz os elementos da transexualidade e travestilidade à tona, faz assumir e aceitar, assim como é elemento de discriminação e produção da violência. Por outro lado, é o corpo do/da transexual que realça sua identidade de gênero, além de que é o corpo a marca física da personalidade, é também este que se faz docilizar pelas transformações, cirurgias, implantes, procedimentos estéticos e uso de hormônios. Assim como é o mesmo corpo que sofre a violência, que é esquartejado, violado e manipulado.

Existem também aqueles corpos que se opõem, que resistem e que enfrentam o sistema binário de gênero que se configura através das possibilidades vaginasmulheres-femininas e homens-pênis-masculinos (Bento, O que é transexualidade, 2008), ou ainda, homem e masculino podem facilmente significar um corpo feminino ou masculino e vice e versa (Butler, 2017).

É na classe quatro que as palavras 'travesti', 'corpo', 'sociedade', 'morrer', 'visibilidade', 'hormônio', 'programa' e 'trabalho' são mais representativas. Como já mencionado, nessa correlação é possível ver o quanto a travestilidade e a transexualidade estão ligadas às questões corporais. Estas, por sua vez, também atravessam a RS de violência.

Ao enunciareım a palavra 'travesti' há a demarcação das diferenças em relação à aceitação, reconhecimento e violências que distinguem as pessoas trans das que são travestis. Se estas identidades são confundidas socialmente, as formas de tratamento também são confusas, o que pode gerar disparidades na aceitação e gerar ainda uma patologização de uma identidade.

Eu tô vendo o pessoal colocando bandeirinha transexual, fazendo tipo auê na internet, fazendo manifestação [em relação à aceitação da transexualidade], porque pra travesti que não tem acesso a nome social é um desconhecimento e marginalização que rola muito e até mesmo apagamento. (Entrevistado I, homem transexual não-binário)

Ser travesti é uma forma de resistência no que eu digo, é a luta diária pela sobrevivência, não é glamour como as pessoas dizem né. (Entrevistada $F$, mulher transexual)

Mas eles estão sempre querendo saber, com a desculpa de que precisam entender e também vinculado à questão de que se ela provavelmente é 
travesti, ela tem disforia de gênero, ela é louca, sabe? (Entrevistada G, travesti, transfeminina, não-binária)

Num segundo momento dessa classe é possível identificar a relevância da expressão 'corpo'. Nessa expressão há a correlação com a aceitação e a diferenciação do que é ou não ser "T". Estas tentativas de definir o que é ser transexual ou travesti ocorrem a partir da relação com o corpo - estar em acordo o físico e o psicológico - ou não. Esse discurso se repete na fala dos entrevistados e tem correlação com o que eles pensam sobre os procedimentos clínicos de redesignação sexual.

É o corpo dela, ela tem direito! Eu acho que mesmo que o hormônio fizesse mal é de pura responsabilidade da pessoa com o corpo dela. (Entrevistada G, travesti, transfeminina, não-binária).

Se, tipo assim, você é uma menina que nasceu num corpo de menino e agora você assumiu como mulher você tem que ser tratada, tipo assim, no mínimo como tal e pronto. (Entrevistada $\mathrm{E}$, mulher transexual)

A questão transexual é a mesma coisa, já é psicológica, a trans ela tem a necessidade porque ela não vê o corpo dela um corpo que ela sente confortável. (Entrevistada G, travesti, transfeminina, não-binária)

O que se percebe nessas falas é que há um resquício do pensamento social da necessidade de adequação do corpo - da genitália, principalmente - à identidade do indivíduo. Entretanto, como já afirmado anteriormente, há que se questionar a necessidade de uma cirurgia para garantir a cura ou a felicidade diante de um corpo que questiona o sujeito e também a sociedade binária.

Por outro lado, no sentido da adequação do corpo às necessidades e desejos da pessoa que se identifica como travesti e transexual, há a expressão 'hormônio' e 'hormonização'. Sendo uma técnica presente tanto para homens ou mulheres trans e travestis, ela diz respeito à eliminação/ganhos de caracteres físicos como barba, voz, etc. Há na fala dos participantes a preocupação, diante da hormonização, se esta prática pode fazer bem ou mal.

Meninas, gurias pequenas, já tomando hormônio porque já entraram no processo da adolescência, na puberdade. [...] É o corpo dela e ela tem direito, então a gente sabe que hormônio não faz mal desde que seja controlado por um endócrino. [...] Algumas tomam qualquer tipo de hormônio e tem elefantíase, trombose, AVC, derrame, porque não têm acesso. Assim se uma pessoa que tem fome não tem acesso a trabalho e comida. (Entrevistada $G$, travesti, transfeminina, não-binária)

[os médicos] Não entende nada de silicone, de hormônio. É porque são omissos mesmo, porque não querem tanto, é que em toda faculdade de medicina a maior que eu sei eles não tá nem aí pra transexual, eles estudam mais o órgão genital. (Entrevistada F, mulher transexual)

Mesmo que seja uma prática corrente à população " $T$ ", deve-se questionar o acesso à hormonioterapia, uma vez que não há muitos registros da atenção a esta especificidade no Sistema Único de Saúde, ao passo que o acesso a profissionais 
habilitados e preparados é precário ou por vezes acontece com muitos questionamentos, discriminação e preconceito. Em muitos casos, meninos e meninas trans optam por buscar na clandestinidade o acesso à hormonização, usando-os sem prescrição médica e avaliação de impacto para a sua saúde.

Essa tentativa de se transformar seria uma prerrogativa de atender às expectativas da sociedade e cessar com a violência? Ou uma tentativa de incluir-se pela padronização esperada? A presença da expressão 'morrer' pode nos auxiliar no entendimento dessa correção sociedade - corpo [dos/das travestis e transexuais] violência.

Atualmente eu faço terapia, exatamente sobre essa questão, para poder aceitar esse corpo no qual eu vivo [...] porque eu cheguei à conclusão: é esse corpo que eu vou habitar o resto da minha vida. (Entrevistado I, homem transexual não-binário)

[sobre a violência que sofreu] Meus amigos e meu namorado vão entrar no meio, são pessoas assim que vão sofrer e podem até morrer por uma coisa que aconteceu comigo, se eu tivesse sozinha, seria outro rolê. (Entrevistada G, travesti, transfeminina, não-binária)

Se alojou na parte que ficava o silicone, aí deu necrose naquele local onde a bactéria se alojou, aí teve que drenar todo o silicone, a parte que morreu ele teve que tirar. (Entrevistada A, mulher transexual)

Por fim, a menor das classes, a classe três foi denominada identidade e gênero, constituída por $14,78 \%$ das falas utilizadas para a análise. Nela, é possível perceber a relação entre a violência e as questões identitárias, o diferente. Para tanto, as expressões mais frequentes nessa classe foram 'homem', 'cisgênero', 'gênero', 'mulher trans', 'cis', 'homem trans', 'identificar', 'mulher', etc. Aqui vemos que a violência, em termos simbólicos, machuca. Pensamos sempre na violência física, mas a identificação e a negação disso nega a eles/elas o direito de serem quem são.

Estão representadas nessa classe a necessidade de diferenciação, de definição o que é ser uma pessoa travesti/transexual, trazendo o que é ser transgênero em oposição ao que é ser cisgênero, corroborando com o que é dito por Bento (2008). Nesse percurso de dispor as diferenças, as pessoas trans/travestis sofrem por terem uma identidade de gênero discrepante à cisgeneridade.

No meio LGBT acredito que não porque é ouvido que o homem gay, porque o homem gay tem privilégios, afinal é um homem. (Entrevistado I, homem transexual não-binário)

Se ninguém nunca chegasse na cabeça de uma criança que provavelmente é criança transgênero e falasse para ela que o corpo de uma mulher é assim e o corpo de um homem é assim, ela ia crescer vendo aquilo que ela tem entre as pernas é errado. (Entrevistada G, travesti, transfeminina, não-binária)

O serviço de saúde já é difícil até para uma pessoa que é um homem ou uma mulher, digamos assim né, heteronormativa, imagina para uma transexual, para uma trans, para uma travesti. (Entrevistada B, mulher transexual) 
Se tiver duas pessoas, dois homens, duas mulheres, se uma for transexual, gay, eles ri na sua cara, entendeu? (Entrevistada B, mulher transexual)

Essas falas demonstram que existem hierarquias dentro da própria comunidade LGBT, o que pode indicar que estas têm relação com as violências que sofrem cada um dos sujeitos com identidades de gênero e orientações sexuais diferentes do que é cisgênero ou heterosexual. A partir desses trechos também é possível notar que a violência está desde a imposição da identidade do que é ser homem ou o que é ser mulher e vai até a diferenciação na convivência social, nas cenas de preconceito, transfobia e exclusão por não ser cisgênero. Há nessa correlação mais uma contribuição para o entendimento da RS de violência para os sujeitos entrevistados, além da mediação do corpo, como na classe quatro, que está intimamente relacionada com a forma como a identidade é assumida, diferenciada e aceita.

\section{Considerações Finais}

A análise das representações sociais da violência para sujeitos transexuais suscita a compreensão que as vivências marcam as formas de pensar, sentir e agir desses sujeitos. Seja desde o processo de assumir a transexualidade/travestilidade para si ou para a família, instituições sociais e atores sociais, ela não acontece de forma sem resistências, sem violência - isso foi possível ser visto a partir das classes dois e um.

A partir da classe quatro pode-se verificar o quanto o elemento 'corpo' media a representação social da violência para sujeitos travestis e transexuais. Essa mediação se dá no corpo físico porque é nele que se sente as principais violências, é devido ao corpo que não se adequa a um padrão binário, cis-hetero-normativo, que as violências acontecem, é o corpo que demanda intervenção e através dele que acontece a relação social. Por outro lado, com a classe três verifica-se o quanto a RS de violência também está relacionada com os processos de diferenciação e identificação, sendo possível entender a partir dos entrevistados que é justamente por isso que a violência acontece.

Não podemos negar que este tema - violência contra a população transgênera - tem provocado a sociedade a se reposicionar e isso interfere diretamente na construção e manutenção das representações sociais. Este estudo mostra as RS a partir dos sujeitos que estão sofrendo tais violências, enfrentando cotidianamente as mudanças sociais, sujeitos tensionados pela materialidade das suas próprias vidas. Porém, este campo de estudo não se esgotou somente aqui. Há a necessidade de fazer com que mais sujeitos " $T$ " se mobilizem a participar das pesquisas que evidenciem as situações vividas por eles/elas. Somente com a enunciação deles/delas é que será possível identificar e combater as violências e as situações degradantes pelas quais eles/elas passam nos seus cotidianos.

Por outro lado, ainda há campo de estudo sobre o tema violência com pessoas

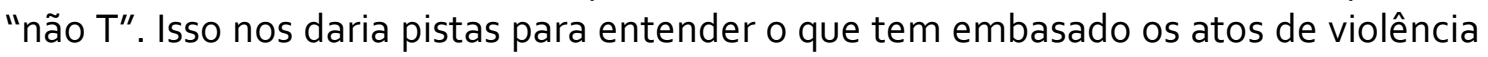
que são sofridos pela população transgênera. Ou seja, o que sujeitos com identidades cisgênero dizem, pensam e fazem sobre as violências junto à população transgênero. 
Como afirmado ao longo da análise, na representação social da violência percebe-se que há resquícios do que tem sido divulgado na mídia sobre a questão da transexualidade e da travestilidade. A visualização da obrigação da "cirurgia de mudança de sexo" dá ares de padronização à população "T", ou seja, há uma doença que há que ser tratada com uma cirurgia, entretanto sabe-se que esta identidade extrapola as questões corporais.

Nesse sentido, embora o processo de transição seja marcado pelas mudanças no corpo, acreditamos que a principal transição vivida pelos sujeitos transgêneros esteja na sua relação com o social. Na verdade, existe uma relação quase cíclica entre essas duas transições, o corpo da pessoa travesti e transexual é normatizado pela vivência social ou, em alguns casos, é utilizado como elemento de resistência às pressões sociais. Porém, estando docilizado/padronizado em uma forma mais aceitável ou sendo ato de resistência, ele é vitimado pelo preconceito, discriminação e agressões. Por vezes, esconder a sexualidade e a identidade é uma forma de ser menos vítima de violências na rua, no trabalho e em casa (Carrieri, Souza, \& Aguiar, 2014; Geoffroy \& Chamberland, 2015).

Sutil, mas presente, a violência contra as pessoas " $T$ " por parte dos profissionais das áreas da saúde e da educação se fizeram notar. Mesmo que existam boas intenções e profissionais atentos às questões das identidades de gênero, ainda há um caminho longo a percorrer, que passa desde a conscientização durante os percursos formativos, desmistifica e desproblematiza a questão, até a proposta e implantação de políticas públicas mais ásperas no que diz respeito à tolerância às diferenças, à diversidade e à atenção às especificidades da população travesti e transexual. Este caminho das políticas públicas deve acompanhar a mudança da sociedade e da cultura.

Este estudo apresenta limitações por trazer apenas nove sujeitos na sua composição e análise, porém demonstra como há um campo profícuo de pesquisas a serem feitas, não somente no limiar de entender o que as pessoas pensam sobre a transexualidade ou a travestilidade, mas estudos que coloquem a população transexual e travesti como sujeitos e participantes ativos de seus processos. Para superar a violência que essa população sofre, é preciso firmar este compromisso de fazer também com que exista protagonismo acadêmico dos mesmos, além de políticas públicas que garantam a efetividade de seus direitos sociais.

\section{Refeferências}

Arán, M., Murta, D., \& Lionço, T. (2009). Transexualidade e saúde pública no Brasil. Ciência \& Saúde Coletiva, 14(4), pp. 1141-1149. doi:http://dx.doi.org/10.1590/S1413-81232009000400020

Arbatani, T., Aqili, S., Labafi, S., \& Omidi, A. (2016). Social representations of iranian transsexual people in the media: a thematic analysis. International Journal of Academic Research in Business and Social Sciences, 6(5), pp. 273-284. doi:10.6007/IJARBSS/v6-i5/2142 
Baptista, G., Silva, O., Menandro, M., \& Bonomo, M. (2016). Representações sociais de homens e mulheres transexuais para estudantes de psicologia. Anais do IV Seminário Internacional de Educação e Sexualidade, (pp. 1-15). Vitória-ES. Fonte: http://www.gepsexualidades.com.br/resources/anais/6/1466680421_AROUIV O_Pessoastranstrabalhocompleto(ultimaversao).pdf

Bento, B. (2008). O que é transexualidade. São Paulo: Brasiliense.

Brasil. (2013). PORTARIA No 2.803, DE 19 DE NOVEMBRO DE 2013 - Redefine e amplia o Processo Transexualizador no Sistema Único de Saúde (SUS). Brasília: Ministério da Saúde. http://bvsms.saude.gov.br/bvs/saudelegis/gm/2013/prt2803_19_11_2013.html

Butler, J. (2017). Problemas de gênero: feminismo e subversão da identidade (13 ${ }^{\mathrm{a}} \mathrm{ed}$.). Rio de Janeiro: Civilização Brasileira.

Camargo, B., \& Justo, A. (2013). Tutorial para uso do software de análise textual IRAMUTEQ. Florianópolis: Laboratório de Psicologia Social da Comunicação e Cognição (LACCOS) - UFSC. www.iramuteq.org/documentation/fichiers/tutoriel-en-portugais

Caravaca-Morera, J., \& Padilha, M. (2017). Social representations of sex and gender among trans people. Revista Brasileira de Enfermagem, 70(6), pp. 1235-1243. doi: http://dx.doi.org/10.1590/0034-7167-2016-0581

Carrieri, A., Souza, E., \& Aguiar, A. (2014). Trabalho, Violência e Sexualidade: Estudo de Lésbicas, Travestis e Transexuais. RAC - Revista de Administração Contemporânea, 18(1), pp. 78-95. Acesso em 25 de novembro de 2017, disponivel em http://www.redalyc.org/articulo.oa?id=84029528006

Cruz, E. F. (2011). Banheiros, travestis, relações de gênero e diferenças no cotidiano da escola. Revista Psicologia Política, 21(11), 73-90. Acesso em 25 de Novembro de 2017, disponível em http://pepsic.bvsalud.org/scielo.php?script=sci_arttext\&pid=S1519$549 \times 2011000100007$

Efrem Filho, R. (2016). Corpos brutalizados: conflitos e materializações nas mortes de LGBT. Cadernos Pagu(46), 311-340. doi:http://dx.doi.org/10.1590/18094449201600460311

Itaqui, L., \& Felippi, G. (2017). Cinema, psicologia e homoafetividade: reflexões das cenas do contemporâneo. Em L. P. Ribeiro, Família(s) e afetividade(s) (pp. 131146). Rio de Janeiro: Gramma.

Jodelet, D. (2005). Experiência e representações sociais. Em M. S. Menin, \& A. d. SHIMIZU, Experiência e representação social: questões teóricas e metodológicas (pp. 23-56). São Paulo: Casa do Psicólogo.

Lanz, L. (2014). O corpo da roupa: a pessoa transgênera entre a transgressão e a conformidade com as normas de gênero. Programa de Pós-Graduação em 
Sociologia, Departamento de Ciências Sociais. Curitiba: Universidade Federal do Paraná.

Matão, M., Miranda, D., Campos, P., Teles, M., \& Mesquita, R. (2010). Representações sociais da transexualidade: perspectiva dos acadêmicos de enfermagem e medicina. Revista Baiana de Saúde Pública, 34(1), pp. 101-118. Fonte: http://files.bvs.br/upload/S/0100-0233/2010/v34n1/a1423.pdf

Moscovici, S. (2012). A psicanálise, sua imagem e seu público. Petrópolis/RJ: Vozes.

Ribeiro, L. P. (2017). O campo, a violência e a educação do campo: representações sociais sobre a violência de educandos do curso de licenciatura em educação do campo. Rio de Janeiro: Gramma.

Ribeiro, L., \& Antunes-Rocha, M. (2016). História, abordagens, métodos e perspectivas da teoria das representações sociais. Psicologia e Sociedade, 28(2), pp. 407-409. doi:http://dx.doi.org/10.159o/1807-03102016v28n2p407

Rocha, Â., Ban, G., \& Valenga, R. (21 de Agosto de 2017). Brasil é o país que mais mata travestis e transexuais no mundo. Fonte: Periódico UEPG: http://periodico.jor.br/index.php/direitos-humanos/669-brasil-e-o-pais-quemais-mata-travestis-e-transexuais-no-mundo

Santos, A. B., Shimizu, H. E., \& Merchan-Hamann, E. (2014). Processo de formação das representações sociais sobre transexualidade dos profissionais de saúde: possíveis caminhos para superação do preconceito. Ciência e Saúde Coletiva, 19(11), pp. 4545-4554. doi:http://dx.doi.org/10.1590/1413812320141911.15702013 .

Silva, G., Souza, E., Sena, R., Moura, I., Sobreira, M., \& Miranda, F. (2016). Situações de violência contra travestis e transexuais em um município do nordeste brasileiro. Revista Gaúcha de Enfermagem, 37(2), pp. 1-7. Acesso em 25 de Novembro de 2017, disponível em http://www.scielo.br/pdf/rgenf/v37n2/01026933-rgenf-1983-144720160256407.pdf

Souza, H., \& Bernardo, M. (2014). Transexualidade: as consequências do preconceito escolar para a vida profissional. Bagoas - estudos gays: gêneros e sexualidades, $\underline{8}(11)$, pp. 157-175. Acesso em 25 de novembro de 2017, disponível em https://periodicos.ufrn.br/bagoas/article/view/6548/5078

Transgender Europe. (30 de Março de 2017). TMM Update Trans Day of Visibility 2017 - Press Release. Fonte: Transgender Europe: http://transrespect.org/en/tdov2017-tmm-update/

Ventura, M. (2010). A transexualidade no tribunal: saúde e cidadania. Rio de Janeiro: EdUERJ.

\section{Cómo referenciar este artículo/How to reference this article:}

Paulo Ribeiro, L.; Bacellar Vilanni, F.; Paulo da Silva, I.; De Souza Alexandre, P.T. (2019). Nos sofremos violência todo dia!: Representações sociais e vivências de violência para pessoas transgêneras. iQUAL. Revista de Género e Igualdad, 2, 22-40, doi: 10.6018/iQual.327291 
Paulo Ribeiro, L.; Bacellar Vilanni, F.; Paulo da Silva, I.; De Souza Alexandre, P.T. (2019). Nos sofremos violência todo dia!: Representações sociais e vivências de violência para pessoas transgêneras [We suffer violence everyday!: social representations and victims of violence for transgenders]. iQUAL. Revista de Género e lgualdad, 2, 22-40, doi: 10.6018/iQual. 327291 